\title{
Методика получения серебросодержащего сорбента на основе бентонита для фиксации соединений радиоиода
}

\author{
(C) 2021 Тюпина Е.А., Прядко А.В., Меркушкин А.О. \\ Российский химико-технологический университет им. Д.И. Менделеева, Москва
}

Поступила в редакцию 9.10.2020 г.

DOI: $10.17308 /$ sorpchrom.2021.21/3216

Работа относится к области радиоэкологии и посвящена защите окружающей среды от радиоактивных изотопов иода. В радиоактивных отходах (РАО) иод находится в анионных формах $\mathrm{I}^{-}$и $\mathrm{IO}_{3}^{-}$, в этих формах возможна миграция радиоиода в окружающую среду. Системы инженерных барьеров безопасности в хранилищах РАО должны предотвращать попадание радионуклидов за пределы хранилища. Их предполагается сооружать из компактированных бентонитовых глин, обладающих высокими водоизоляционными и катионообменными свойствами, но не сорбирующими анионы. Следовательно, требуется модификация бентонитов для придания им способности сорбировать иод, перспективным вариантом которой является нанесение серебра с последующим переводом его в соединения, подходящие для фиксации любых подвижных форм радиоиода. Существует ряд методик нанесения серебра на различные материалы, однако, они отличаются трудоёмкостью или не позволяют равномерно наносить серебро на пористые материалы.

В данной работе навеску нитрата серебра растворяли в дистиллированной воде и вносили двукратный мольный избыток гидроксида натрия. Выпавший осадок оксида серебра растворяли, добавляя по каплям концентрированный раствор аммиака. Затем в раствор добавляли гексаметилентетрамин (ГМТА). Объём готового раствора был равен водоёмкости навески бентонита с небольшим избытком. Раствор вносили в бюкс с известной навеской бентонита и оставляли на 25 часов для полного набухания материала. Затем бюкс выдерживали в течение 24 часов в сушильном шкафу при $90^{\circ} \mathrm{C}$. При повышенной температуре происходил термический гидролиз ГМТА с выделением формальдегида, который восстанавливал серебро до металла. Для определения количества нанесённого серебра бентонит обрабатывали 2 см $^{3} 3 \mathrm{M}$ азотной кислоты и титровали полученный раствор стандартизированным раствором роданида аммония в присутствии ионов $\mathrm{Fe}^{3+}$. Согласно результатам титрования, выход восстановленного серебра, осаждённого на поверхность бентонита составил 95\% от внесённого количества. Электронную микроскопию и энергодифракционную спектроскопию (ЭДС) проводили на сканирующем электронном микроскопе TESCAN VEGA 3. На ЭДС-спектре присутствует отчётливый пик на энергии 2.984 кЭв, свидетельствующий о присутствии серебра на поверхности частиц исследованного образца, которое как показало рентгеновское картирование, распределено по поверхности бентонита равномерно.

Разработана эффективная методика равномерного нанесения металлического серебра на бентонит с высоким выходом (95\%) для последующего перевода его в соединения, подходящие для фиксации любых подвижных форм радиоиода, например, растворимой анионной формы радиоиода в хранилищах РАО.

Ключевые слова: бентонит, радиоактивные отходы, иод, сорбция, серебро, гексаметилентетрамин

\section{Введение}

В результате деятельности предприятий ядерно-топливного цикла происхо- дит образование радиоактивных изотопов иода, среди которых наибольшую угрозу представляют ${ }^{129} \mathrm{I}$ и ${ }^{131} \mathrm{I}$. Высокая подвижность, токсичность и большой период полураспада (в случае ${ }^{129} \mathrm{I}$ ) делают 
радиоиод опасным для человека и окружающей среды. Иммобилизация радиоактивного иода в отходы происходит преимущественно в виде подвижных форм иодид-аниона $\mathrm{I}^{-}$и иодат-аниона $\mathrm{IO}_{3}^{-}[1]$, в этих формах, а также в виде иодорганических соединений, происходит миграция растворённого радиоиода в окружающей среде $[2,3]$. Таким образом, необходимы сорбенты для очистки воды (например, подземной) от радиоактивных изотопов иода. В частности, необходима защита окружающей среды от радиоиода с помощью противомиграционных барьеров хранилищ РАО в глубинных геологических формациях. В качестве материала таких барьеров рассматриваются компактированные бентонитовые глины, обладающие высокими гидроизоляционными и катионообменными свойствами $[4,5]$, но не способными сорбировать анионы [3]. Включение в состав барьера некоторого количества модифицированного бентонита, способного сорбировать иод, позволит сохранить эксплуатационные свойства бентонитов и обеспечить защиту окружающей среды от радиоиода. Однако большинство методик модификации бентонита направлены на повышение его катионообменных свойств [6 - 9], что не приводит к улучшению фиксации радиоиода, представленному анионными формами.

Задачей данной работы является разработка эффективной методики количественного и равномерного нанесения серебра в металлической форме на бентонит для последующего перевода его в соединения, подходящие для фиксации любых форм радиоактивного иода.

Соединения серебра и сорбенты, содержащие серебро, являются одними из наиболее эффективных для улавливания иода как в ионной форме [10] из водной среды, так и из воздуха в формах $\mathrm{I}_{2}$ и $\mathrm{CH}_{3} \mathrm{I}$ [1]. Нанесённое на сорбент металлическое серебро может быть затем легко переведено в другую форму, например, окислено до $\mathrm{Ag}_{2} \mathrm{O}$, который эффективен для улавливания иодметана $[11,12]$, или до $\mathrm{AgCl}$, способного поглощать из раствора иодид- и иодат-ионы [13]. При этом важно обеспечить количественное и равномерное нанесение серебра, что позволит максимально эффективно использовать всю поверхность сорбента.

\section{Теоретическая часть}

Существует ряд методик нанесения серебра на различные материалы. В работе [14] морденит переводили в $\mathrm{Ag}^{+}$-форму и восстанавливали серебро до $\mathrm{Ag}^{0}$ в токе водорода в течение 12 часов при температуре $150^{\circ} \mathrm{C}$. Для синтеза сорбента «Физхимин» силикагель КСКГ пропитывали водным раствором нитрата серебра $\mathrm{AgNO}_{3}$ и восстанавливали $\mathrm{Ag}^{+}$до свободного серебра с помощью гидразингидрата $\mathrm{N}_{2} \mathrm{H}_{4}$, гидроксиламина $\mathrm{NH}_{2} \mathrm{OH}$ или аммиака [15]. Схожая методика была применена другими авторами [16]: на материал, выдержанный в растворе нитрата серебра, воздействовали избытком растворов $\mathrm{NaOH}$ и гидразина в виде гидрата или сульфата. В работе [17] мезопористый силикагель выдерживали в водно-этанольном растворе $\mathrm{AgNO}_{3}$, серебро восстанавливали раствором борогидрида натрия $\mathrm{NaBH}_{4}$.

Описанные выше методики имеют ряд недостатков: высокая трудоёмкость и опасность вследствие использования взрывоопасных (газообразный водород) [14] или токсичных (гидразин и гидроксиламин) реагентов $[15,16]$. Так же в работе [15], например, стадия пропитки и сушки не позволяет добиться получения равномерного слоя восстановленного серебра, которое концентрируется на поверхности локально вследствие кристаллизации в процессе высушивания. Кроме того, в случае материалов с развитой пористостью, действие капиллярных сил приводит к локализации кристаллов соли преимущественно на внешней поверхности гранул.

Альтернативой могут служить методы, основанные на протекании реакции «серебряного зеркала». Так, в работах $[18,19]$ серебро наносили на инертный 
носитель восстановлением аммиачного комплекса серебра глюкозой. В [20] получали нанокластеры серебра, выдерживая смесь свежего раствора $\mathrm{Ag}\left[\left(\mathrm{NH}_{3}\right)_{2}\right]^{+}$и растворов глюкозы и винной кислоты в течение нескольких часов. Очевидно, что скорость реакции восстановления в подобных методах является ключевым фактором, влияющим на свойства получаемого покрытия. Быстродействующие восстановители, такие, как глюкоза, растворы ацетальдегида или формальдегида, хорошо подходят для нанесения серебра на материалы с относительно неразвитой поверхностью, например, на стекло или непористую керамику. Однако высокая скорость реакции восстановления серебра в этом случае не позволит ему проникнуть достаточно глубоко внутрь пористых частиц или их агрегатов. Для нанесения серебра на бентонит необходим восстановитель, действующий не сразу, а спустя время, достаточное для равномерного объёмного распределения серебра вследствие его диффузии вглубь пористых частиц.

\section{Экспериментальная часть}

Для нанесения серебра на бентонит готовили маточный раствор объёмом, равным водоёмкости навески бентонита с небольшим избытком. Навеску нитрата серебра (х.ч.), соответствующую расчётному содержанию серебра на бентоните $1 \%$ масс., растворяли в дистиллированной воде и добавляли раствор, содержащий двукратный мольный избыток гидроксида натрия. Выпавший осадок $\mathrm{Ag}_{2} \mathrm{O}$ растворяли, по каплям добавляя концентрированный раствор аммиака. К полученному раствору аммиачного комплекса серебра добавляли раствор с пятикратным мольным избытком гексаметилентетрамина (ГМТА, $\mathrm{C}_{6} \mathrm{H}_{12} \mathrm{~N}_{4}$ ). Избыток соответствующих реагентов был определен в ходе экспериментов по оптимизации скорости реакции нанесения серебра. Маточный раствор вносили в бюкс с навеской бентонита и выдерживали в течение 25 часов до полной пропитки материала
[21], после чего помещали в сушильный шкаф, разогретый до $90^{\circ} \mathrm{C}$ [22] на 24 часа. Время реакции было подобрано экспериментально на основании максимального содержания серебра в бентоните.

Для определения содержания серебра в бентоните, навеску 0,5 г бентонита обрабатывали $2 \mathrm{~cm}^{3} 3 \mathrm{M}$ азотной кислоты в течение 48 часов (оптимальные условия были подобраны в ходе предварительных экспериментов). Суспензию центрифугировали при 6000 об/мин в течение 10 минут и проводили определение серебра в центрифугате титрованием стандартизированным по навеске $\mathrm{AgNO}_{3}$ раствором роданида аммония, как описано в работе [15]. Бентонит затем распускали в небольшом количестве дистиллированной воды, центрифугировали и снова определяли серебро в центрифугате описанным выше способом. Эту операцию повторяли до тех пор, пока в центрифугате не переставали определяться ионы $\mathrm{Ag}^{+}$.

Микроскопия и рентгеновское картирование образцов были выполнены с помощью сканирующего электронного микроскопа TESCAN VEGA 3 (Чехия).

\section{Обсуждение результатов}

Маточный раствор, которым пропитывается бентонит, содержит реактив Толленса $\left[\mathrm{Ag}\left(\mathrm{NH}_{3}\right)_{2}\right]^{+}[23]$ и ГМТА. Он может длительное время храниться при комнатной температуре, не обнаруживая видимых признаков восстановления серебра, что позволяет компонентам раствора проникнуть глубоко в поры материала и равномерно распределиться по всему объёму. При нагревании до $90^{\circ} \mathrm{C}$ происходит термический гидролиз ГМТА с образованием формальдегида и аммиака [22]:

$$
\mathrm{C}_{6} \mathrm{H}_{12} \mathrm{~N}_{4}+6 \mathrm{H}_{2} \mathrm{O} \leftrightarrow 6 \mathrm{CH}_{2} \mathrm{O}+4 \mathrm{NH}_{3} \quad \text { (1) }
$$

Высвобождающийся формальдегид является быстродействующим восстановителем, который взаимодействует с реактивом Толленса с осаждением металлического серебра [24] на внешней и внутренней поверхности бентонита. 

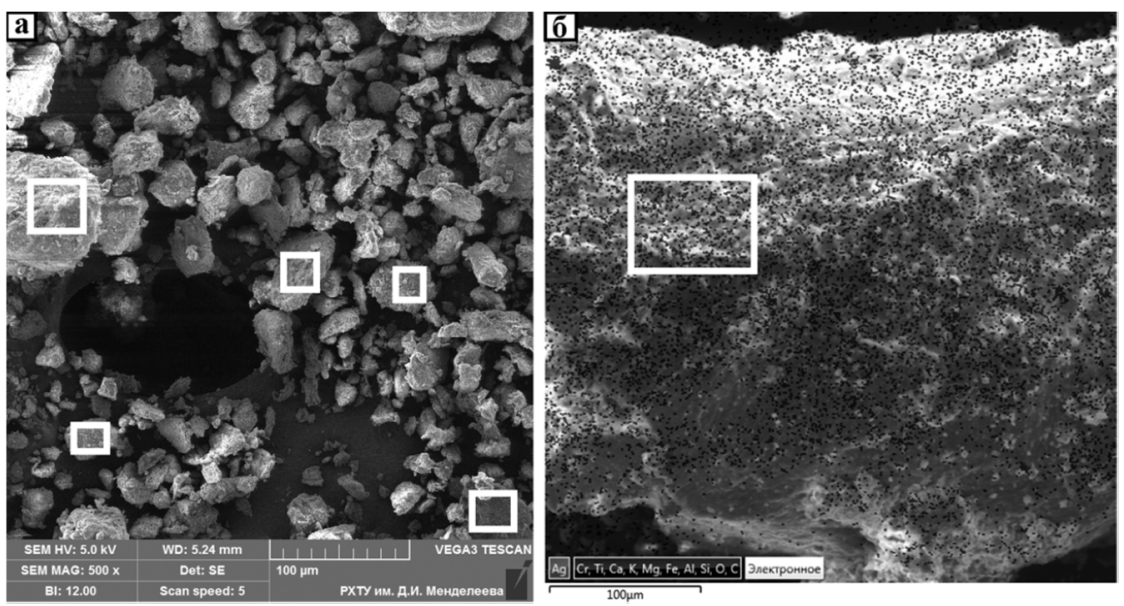

Рис. 1. Микрофотография бентонита с нанесённым серебром (a), рентгеновское картирование одной из областей, выделенных на рис. 1а (б).

Fig. 1. Micrograph of bentonite with deposited silver (a),

$\mathrm{X}$-ray mapping of one of the areas highlighted in Fig. 1a (b)

Результаты титрования показали, что 95\% серебра от внесённого количества оседает на бентоните в виде металла. Варьируя продолжительность выдержки бентонита в маточном растворе, можно регулировать глубину проникновения серебра в поры сорбента.

Микрофотографии бентонита с нанесённым серебром и рентгеновское картирование, показывающее распределение серебра на поверхности образца, представлены на рисунке 1 . На рисунке 2 показан энергодисперсионный спектр (ЭДС) исследованного образца.

Элементный состав всех областей, показанных на рисунке 1a, был близким, поэтому приведены результаты только одного анализа. На рентгеновской карте (рис. 1б) видно, что металлическое серебро распределено равномерно по поверхности образца. На ЭДС-спектре (рис.2) присутствует отчётливый пик на энергии 2.984 кЭв, свидетельствующий о присутствии серебра на поверхности частиц исследованного образца.

\section{Заключение}

Разработана эффективная методика равномерного нанесения металлического серебра на бентонит с высоким выходом (95\%) для последующего перевода его в соединения, подходящие для фиксации любых подвижных форм радиоиода, например, растворимой анионной формы радиоиода в хранилищах РАО.

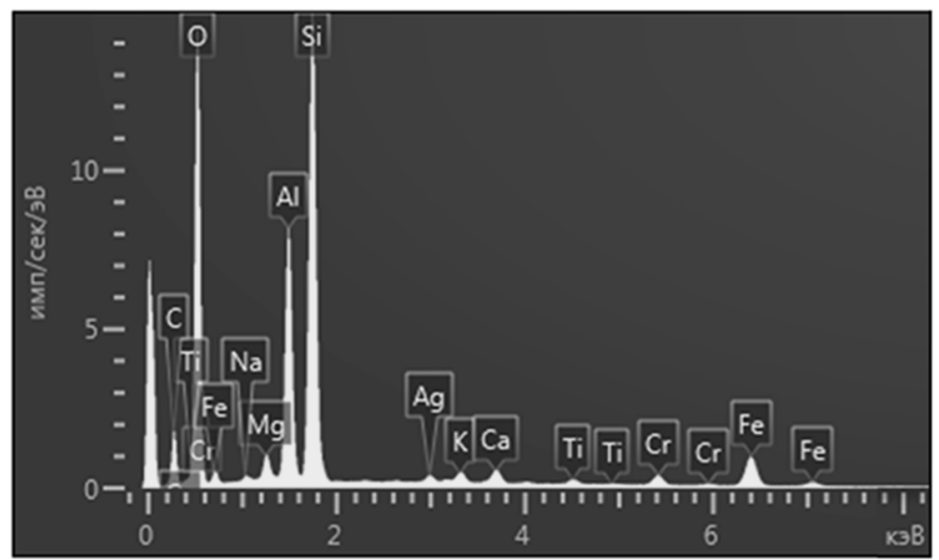

Рис. 2. Энергодсперсионный спектр области, выделенной на рис. 16.

Fig. 2. The energy dispersive spectrum of the region shown in Fig. $1 b$. 


\section{Список литературы}

1. Riley B.J., Vienna J.D., Strachan D.M. et al. // J. of Nuclear Mat. 2016. Vol. 470. pp. 307326. DOI: https://doi.org/10.1016/j.jnucmat. 2015.11.038

2. Кулюхин С.А., Каменская А.Н., Коновалова Н.А. // Радиохимия. 2011. Т. 53. № 2. C. 107-123.

3. Neeway J.J., Kaplan D.I, Bagwell C.E. et al. // Sci. Tot. Environ. 2019. Vol. 691. pp. 466475. DOI: https://doi.org/10.1016/j.scitotenv.2019.07.146

4. Крупская В.В., Закусин С.В., Лехов В.А. и др. // Радиоактивные отходы. 2020. № 1 (10). C. 35-55.

5. Крупская В.В., Закусин С.В., Тюпина Е.А. и др. // Горный журнал. 2016. № 2. С. 8187.

6. Милютин В.В., Гелис В.М., Некрасова Н.А. и др. // Радиохимия. 2012. Т. 54. № 1. С. 71-74.

7. Свиридов А.В., Юрченко В.В., Свиридов В.В. и др. // Сорбиионные и хроматографические прочессы. 2017. Т. 17. № 3. С. 506512.

8. Тучкова А.И., Тюпина Е.А., Рахимов М.Г. // Успехи в химии и химической технологии. 2012. Т. 26. № 6 (135). С. 92-95.

9. Закусин С.В., Крупская В.В., Доржиева О.В. и др. // Сорбиионные и хроматографические прочессы. 2015. Т. 15. № 6. С. 874883.

10. Moore R.C., Pearce C.I., Morad J.W. et al. // Sci. Tot. Environ. 2020. Vol. 716. 132820. DOI: https://doi.org/10.1016/j.scitotenv.2019. 06.166

11. Меркушкин А.О., Обручиков А.В. // Актуальные проблемы гуманитарных и естественных наук. 2014. № 5-1. С. 22-25.

12. Obruchikov A.V., Merkushkin A.O., Zakatilova E.I. // Glass Ceram. 2016. Vol. 73. No
7-8. pp. 240-245. DOI: https://doi.org/10.1007/ s10717-016-9865-0

13. Mostafa M., Ramadan H.E., El-Amir M.A. // J. Environ. Rad. 2015. Vol. 150. pp. 919. DOI: https://doi.org/10.1016/j.jenvrad.2015. 07.022

14. Nenoff T.M., Rodriguez M.A., Spelberg N.R. et al. // Micro. Meso. Mat. 2014. Vol. 200. pp. 297-303. DOI: https://doi.org/10.1016/j.micromeso.2014.04.041

15. Кулюхин С.А., Михеев Н.Б., Каменская А.Н. и др. Патент РФ. № RU2346346C2. 2009.

16. Richard H., Karg V., Schonfeld T. // J. Rad. Nucl. Chem. 1984. Vol. 82/1. pp. 81-91. DOI: https://doi.org/10.1007/bf02227331

17. Mnasri N., Charnay C., de Ménorval L-C. et al. // Micro. Meso. Mat. 2014. Vol. 196. pp. 305-313. DOI: https://doi.org/10.1016/j.micromeso.2014.05.029

18. Гришина Я.С., Обручиков А.В. // Успехи в химии и химической технологии. 2019. T. 23. № 9. C. 10-12.

19. Chen Z., Qiao F., Liu W. // Vacuum. 2020. Vol. 173. 109110. DOI: https://doi.org/10.1016/ j.vacuum.2019.109110

20. Qu L., Dai L. // J. Phys. Chem. 2005. Vol. 109. No 29. pp. 13985-13990. DOI: https://doi.org/10.1021/jp0515838

21. Смолко В.А., Антошкина Е.Г. // Вестник ЮУрГУ. Серия Металлургия. 2014. Т. 14. № 2. C. 89-91.

22. Feng W., Wang B., Huang P. // Mat. Sci. Semi. Proc. 2016. Vol. 41. pp. 462-469. DOI: https://doi.org/10.1016/j.mssp.2015.10.017

23. Пятницкий И.В., Сухан В.В. Аналитическая химия серебра. М. Наука. 1975. 262 с.

24. Райд К. Курс физической органической химии. М. Мир. 1972.576 с. 


\title{
A technique for obtaining bentonite-based silver-containing sorbent for the uptake of radioiodine compounds
}

\author{
(C) 2021 Tyupina E.A., Pryadko A.V., Merkushkin A.O. \\ D. Mendeleev University of Chemical Technology of Russia, Moscow, Russian Federation
}

\begin{abstract}
The study is relevant to radioecology and is devoted to the protection of the environment from radioactive iodine isotopes. In radioactive waste (RW), iodine is present in anionic species $\mathrm{I}^{-}$and $\mathrm{IO}_{3}{ }^{-}$In these species, radioiodine migration into the environment is possible. The engineering barrier system in a nuclear waste repository should prevent the penetration of radionuclides outside the nuclear waste repository. They are supposed to be built from compacted bentonite clays, which have high waterproofing and cation-exchange properties, but do not absorb anions. Consequently, a modification of bentonites is required in order to make them capable of absorbing iodine, a promising option for which is the deposition of silver with its subsequent transfer into compounds suitable for fixing any mobile forms of radioiodine. There are a number of techniques for applying silver to various materials, however, they are either laborious or do not allow a uniform application of silver on porous materials.

In this study, a weighed portion of silver nitrate was dissolved in distilled water and a two-fold molar excess of sodium hydroxide was added. The precipitated silver oxide was dissolved by adding a concentrated ammonia solution in a dropwise manner. Then hexamethylenetetramine (HMTA) was added to the solution. The volume of the resulting solution was equal to the water capacity of the bentonite sample with a slight excess. The solution was introduced into a weighing bottle with a known weighed amount of bentonite and left for 25 hours for the complete swelling of the material. Then the bottle was kept for 24 hours in an oven at 90 ${ }^{\circ} \mathrm{C}$. At elevated temperatures, the thermal hydrolysis of HMTA occurred with the release of formaldehyde, which reduced silver to metal. For the determination of the amount of deposited silver, bentonite was treated with $2 \mathrm{ml}$ of $3 \mathrm{M}$ nitric acid and the resulting solution was titrated with a standardized solution of ammonium thiocyanate in the presence of $\mathrm{Fe}^{3+}$ ions. According to the titration results, the yield of reduced silver deposited on the surface of bentonite was $95 \%$ of the applied amount. Electron microscopy and energy dispersive spectroscopy (EDS) were performed using a TESCAN VEGA 3 scanning electron microscope. The EDS spectrum had a distinct peak at an energy of $2.984 \mathrm{keV}$, indicating the presence of silver on the surface of the particles of the studied sample, which, as was shown by X-ray mapping, was evenly distributed over the bentonite surface.

An efficient technique has been developed for the uniform deposition of metallic silver on bentonite with a high yield $(95 \%)$ for its subsequent conversion into compounds suitable for fixing any mobile forms of radioiodine, for example, the soluble anionic form of radioiodine in a nuclear waste repository.
\end{abstract}

Keywords: bentonite, radioactive waste, iodine, sorption, silver, hexamethylenetetramine

\section{References}

1. Riley B.J., Vienna J.D., Strachan D.M. et al., J. of Nuclear Mat., 2016, Vol. 470, pp. 307326. DOI: https://doi.org/10.1016/j.jnucmat. 2015.11.038

2. Kulyuhin S.A., Kamenskaja A.N., Konovalova N.A., Radiohimija, 2011, Vol. 53. No 2, pp. 107-123.

3. Neeway J.J., Kaplan D.I, Bagwell C.E. et al. Sci. Tot. Environ., 2019, Vol. 691, pp. 466-475. DOI: https://doi.org/10.1016/j.scitotenv.2019. 07.146

4. Krupskaja V.V., Zakusin S.V., Lehov V.A. et al. Radioaktivnye otkhody, 2020, No 1 (10), pp. 35-55

5. Krupskaja V.V., Zakusin S.V., Tjupina
E.A. et al., Gornyj Zhurnal., 2016, No 2, pp. 8187.

6. Miljutin V.V., Gelis V.M., Nekrasova N.A. et al., Radiokhimija, 2012, Vol. 54, No 1, pp. 7174.

7. Sviridov A.V., Jurchenko V.V., Sviridov V.V. et al., Sorbtsionnye i khromatograficheskie protsessy, 2017, Vol. 17, No 3, pp. 506-512.

8. Tuchkova A.I., Tjupina E.A., Rahimov M.G., Uspekhi $v$ khimii $i$ khimicheskoj tekhnologii, 2012, Vol. 26, No 6 (135), pp. 9295.

9. Zakusin S.V., Krupskaja V.V., Dorzhieva O.V. et al., Sorbtsionnye i khromatograficheskye protsessy, 2015, Vol. 15, No 6, pp. 874-883. 
10.Moore R.C., Pearce C.I., Morad J.W. et al., Sci. Tot. Environ., 2020, Vol. 716, 132820. DOI: https://doi.org/10.1016/j.scitotenv.2019.06.166

11.Merkushkin A.O., Obruchikov A.V., Aktualnye problemy gumanitarnyh $i$ estestvennyh nauk, 2014, No 5-1, pp. 22-25.

12.Obruchikov A.V., Merkushkin A.O., Zakatilova E.I., Glass Ceram., 2016, Vol. 73, No 7-8, pp. 240-245. DOI: https://doi.org/ 10.1007/s10717-016-9865-0

13.Mostafa M., Ramadan H.E., El-Amir M.A., J. Environ. Rad., 2015, Vol. 150, pp. 9-19. DOI: https://doi.org/10.1016/j.jenvrad.2015.07.022

14.Nenoff T.M., Rodriguez M.A., Spelberg N.R. et al., Micro. Meso. Mat,. 2014, Vol. 200, pp. 297-303. DOI: https://doi.org/10.1016/j.micromeso.2014.

04.041

15.Kulyuhin S.A., Mikheev N.B., Kamenskaya A.N. et al., Patent RF, No RU2346346C2. 2009.

16.Richard H., Karg V., Schonfeld T., J. Rad. Nucl. Chem., 1984, Vol. 82/1, pp. 81-91. DOI: https://doi.org/10.1007/bf02227331

Тюпина Екатерина Александровна - доцент кафедры химии высоких энергий и радиоэкологии, к.т.н., доцент, Российский химикотехнологический университет им. Д.И. Менделеева. Москва

Прядко Артем Викторович - аспирант кафедры химии высоких энергий и радиоэкологии, Российский химико-технологический университет им. Д.И. Менделеева, Москва

Меркушкин Алексей Олегович - доцент кафедры химии высоких энергий и радиоэкологии, к.х.н., Российский химико-технологический университет им. Д.И. Менделеева, Москва
17.Mnasri N., Charnay C., de Ménorval L-C. et al., Micro. Meso. Mat., 2014, Vol. 196, pp. 305-313. DOI: https://doi.org/10.1016/ j.micromeso.2014.05.029

18.Grishina Ya.S., Obruchikov A.V., Uspekhi $v$ khimii I khimicheskoj tekhnologii, 2019, Vol. 23, No 9, pp. 10-12.

19.Chen Z., Qiao F., Liu W., Vacuum, 2020, Vol. $173, \quad 109110 . \quad$ DOI: https://doi.org/10.1016/j.vacuum.2019.109110

20.Qu L., Dai L., J. Phys. Chem., 2005, Vol. 109, No 29, pp. 13985-13990. DOI: https://doi.org/10.1021/jp0515838

21.Smolko V.A., Antoshkina E.G., Vestnik JuUrGU. Serija «Metallurgija», 2014, Vol. 14, No 2, pp. 89-91.

22.Feng W., Wang B., Huang P., Mat. Sci. Semi. Proc., 2016, Vol. 41, pp. 462-469. DOI: https://doi.org/10.1016/j.mssp.2015.10.017

23.Pjatnickij I.V., Sukhan V.V., Analiticheskaja khimija serebra, M., Nauka publ, 1975, $262 \mathrm{p}$

24.Rajd K., Kurs Fizicheskoj organicheskoj khimii, M., Mir publ, 1972, 576 p.

Tyupina Ekaterina A. - associate prof., Ph.D (engineering), associate prof., department of chemistry of high energy and radioecology, D. Mendeleev University of Chemical Technology of Russia, Moscow, e-mail: tk1972@mail.ru

Pryadko Artem V. - the post-graduate student, department of chemistry of high energy and radioecology, D. Mendeleev University of Chemical Technology of Russia, e-mail: pryadkoa1557@yandex.ru

Merkuskin Aleksey O. - associate prof., Ph.D (chemistry), department of chemistry of high energy and radioecology, D. Mendeleev University of Chemical Technology of Russia, Moscow, email: polaz@mail.ru 